ASTHMA

\title{
Deaths certified as asthma and use of medical services: a national case-control study
}

\author{
P M Sturdy, B K Butland, H R Anderson, J G Ayres, J M Bland, B D W Harrison, \\ C Peckitt, C R Victor, on behalf of the National Asthma Campaign Mortality and \\ Severe Morbidity Group
}

See end of article for authors' affiliations .....

Correspondence to: Professor H R Anderson, Division of Community Health Sciences, St George's, University of London, London SW17 ORE, UK; r.anderson@ sghms.ac.uk

Received 25 March 2004 Accepted 14 July 2005 Published Online First 29 July 2005
Background: Studies have linked asthma death to either increased or decreased use of medical services. Methods: A population based case-control study of asthma deaths in 1994-8 was performed in 22 English, six Scottish, and five Welsh health authorities/boards. All 681 subjects who died were under the age of 65 years with asthma in Part I on the death certificates. After exclusions, 532 hospital controls were matched to 532 cases for age, district, and date of asthma admission/death. Data were extracted blind from primary care records.

Results: The median age of the subjects who died was 53 years; $60 \%$ of cases and $64 \%$ of controls were female. There was little difference in outpatient attendance (55\% and 55\%), hospital admission for asthma (51\% and 54\%), and median inpatient days (20 days and 15 days) in the previous 5 years. After mutual adjustment and adjustment for sex, using conditional logistic regression, three variables were independently associated with asthma death: fewer general practice contacts lodds ratio $0.82195 \%$ confidence interval (Cl) 0.74 to 0.91$)$ per 5 contacts) in the previous year, more home visits $(1.14(95 \% \mathrm{Cl}$ 1.08 to 1.21$)$ per visit) in the previous year, and fewer peak expiratory flow recordings $10.83(95 \% \mathrm{Cl}$ 0.74 to 0.92 ) per occasion) in the previous 3 months. These associations were similar after adjustment for markers of severity, psychosocial factors, systemic steroids, short acting bronchodilators and antibiotics, although the association with peak flow was weakened and just lost significance.

Conclusion: Asthma death is associated with less use of primary care services. Both practice and patient factors may be involved and a better understanding of these may offer possibilities for reducing asthma death. b England and Wales, mortality from asthma halved between 1986 and 1999 but, despite incentives in general practice and continued improvements in asthma care, 2387 people under the age of 65 years died from asthma in the 5 years between 1994 and 1998. ${ }^{1}$ Many of these asthma deaths were considered preventable by a number of UK confidential enquiries which all pointed to underuse of medical services as a possible contributory factor..$^{2-8}$

The risk of asthma death or near fatal episodes and use of medical services have been investigated in previous casecontrol studies. ${ }^{9-14}$ Some found no association between asthma death (and near fatal episodes) and use of medical services $^{11}{ }^{14}$ while others linked death to increased $^{9}$ or decreased ${ }^{12}$ use of services. Against this background and to redress shortcomings of previous investigations, we carried out a large population based study of cases (asthma deaths) and controls and their use of health services in the previous 5 years.

\section{METHODS}

\section{Cases and controls}

The study of asthma deaths between 1994 and 1998 (inclusive) was undertaken in the same regions of England, Scotland, and Wales as the confidential enquiries into asthma deaths. The study areas, covering $27 \%$ of the British population, were East Anglia, West Midlands, Northampton and Kettering, North Essex, Northern Region (Cumbria and districts north of the Tyne), all Wales and Scotland (Glasgow, Lothian, Argyle and Clyde, Lanarkshire, Ayrshire and Arran, and Forth Valley). In Scotland the time period was reduced to 3 years (1996-8) because of delays in ethics approval and destruction of most of the pre-1996 records.
The Office for National Statistics and the General Register Office provided lists of asthma deaths in subjects under the age of 65 years (9th revision of the international classification of diseases (ICD9 493)). The entry criteria were that asthma was mentioned in Part I of the death certificate, that the underlying cause was not cancer or other conditions unrelated to chronic respiratory disease, and that there was evidence in primary care records of asthma in life. Since asthma may be a risk factor for chronic obstructive pulmonary disease (COPD),,$^{15}$ mention of the latter was not a reason for exclusion. We did not include cases with asthma recorded in Part 2 of the certificate. Details of entry criteria have been dealt with in a previous paper. ${ }^{16}$

Live hospital controls with a primary discharge diagnosis of asthma (ICD 493) were used because of the difficulty in selecting community controls with severe asthma and the importance of controlling for severity as a potential confounding factor. ${ }^{16}$ Sampling frames were set up from discharge lists obtained from the hospitals where asthma deaths occurred (or the nearest hospitals to the community deaths). One control was matched with each case firstly for admission date within 6 months of the date of death (index date) and then age (within 5 years and under age 65 years). ${ }^{16}$

Ethics approval was obtained from the South Thames Multicentre Research Ethics Committee and local research ethics committees.

\section{Data collection and extraction}

Service use data based on any mention in primary care records in the previous 5 years were extracted in the academic department, blind to case-control status from photocopied and anonymised primary care records. Data 


\section{Box 1 Medical care factors investigated}

Medical care factors mentioned in primary care records:

- All practice contacts (excluding requests for prescriptions)

- Respiratory consultations (including upper respiratory tract infections)

- Home visits

- Home visits for respiratory illness

- Visits to a primary care based asthma clinic

- Use of home nebuliser

- Asthma drug non-compliance

- Poor inhaler technique

- Repeated non-attendance for asthma care

- Peak expiratory flow (PEF) recordings (excluding selfrecording)

- Forced expiratory volume in 1 second $\left(\mathrm{FEV}_{1}\right)$ recordings

- Prescription of systemic steroids, short acting bronchodilators, and antibiotics (both on paper and electronic)

- Use of home oxygen

- Wheelchair use

Secondary care factors mentioned in primary care records:

- Outpatient attendance (from hospital letters to general practitioners)

- Acute asthma admissions (validated against hospital records)

- Inpatient days for asthma admission (validated against hospital records)

- Accident and emergency department attendance for asthma

- PEF recordings (from hospital letters to general practitioners and excluding self-recording)

- $\mathrm{FEV}_{1}$ recordings (from hospital letters to general practitioners)

- Prescription of systemic steroids, short acting bronchodilators, and antibiotics (in discharge and outpatient letters)

beyond the 5 years were extracted non-blind in the practice. These were ever mentioned COPD, family history of asthma, evidence of atopy (eczema or hay fever), major nonrespiratory illness, obesity, smoking, and psychosocial factors. ${ }^{16}$ With respect to previous hospital admissions for asthma, hospital records were used to validate the discharge diagnosis, the length of hospital stay, and the exclusion of the index admission (where appropriate). This could not be done totally blind to status.

\section{Use of primary and secondary care services}

The use of medical service factors are listed in box 1. Data for 5 years before the index date were analysed as the year immediately before the event and 4 years before that. For recording of lung function and prescription of asthma drugs, we further divided the time period in the last year into the 3 months before the index date and the 9 months before that. When more than one lung function test was taken at a single consultation it was counted as "one occasion" and self-reporting was not taken into account.

\section{Statistical methods}

Data were analysed by fitting a series of conditional logistic regression models in Stata (Stata Statistical Software Release 5.0, Stat Corporation, College Station, Texas, USA). Selected variables that were significantly associated $(p<0.05)$ with asthma death in the preliminary analysis were then entered into the same model along with sex in order to investigate independent effects. After mutual adjustment, other variables were added to the model to adjust for markers of asthma severity (such as co-morbidity with COPD, age of asthma onset, prescription of home oxygen, and mention of wheelchair), asthma drugs (prescription of systemic steroids and antibiotics in the 3 months before the index date and short acting bronchodilators in the $1-5$ years before the index date), and potential confounding factors (such as obesity, social and psychological factors). We did not adjust for the prescription of inhaled steroids as, in our previous analysis, ${ }^{17}$ they were not significantly associated with asthma death. However, we did investigate their effects as a potential confounder in sensitivity analyses. Finally, interaction terms were added one at a time to investigate whether associations differed in magnitude and/or direction between age groups $(<45, \geqslant 45)$.

The results are presented as odds ratios and approximate 95\% confidence intervals (based on the $t$ distribution). Statistical significance was assessed using the likelihood ratio test. For continuous variables where odds ratios were calculated on the grouped data for presentation, the overall $p$ values were performed based on the continuous data. If age at asthma onset was recorded only as "in childhood" (as it was for $4.4 \%$ of subjects), this was assumed to be 6 yearsthat is, the median value for those with specified ages under 18 years.

The methods used for our investigation of prescribed drugs and asthma are described in another paper. ${ }^{17}$ As already reported, subsequent to the analysis we found that a proportion of controls had been coded for prescribed drugs that related to the index admission or beyond. ${ }^{17}$ Although this will have affected the coding of systemic steroids and antibiotic prescription in the previous $0-3$ months, short acting bronchodilator prescription in the 1-5 year period should be unaffected by coding errors close to the index date. The effect of using an alternative adjustment for asthma drugs informed by results from our previous paper $^{17}$ but based solely on prescription in the previous 4-12 months and $1-5$ years was also investigated.

\section{RESULTS}

\section{Cases and controls}

We identified 681 asthma deaths; 149 (22\%) were excluded because of missing records $(n=82,12 \%)$, miscoding $(n=33$, $5 \%)$, refusal or non-response from general practitioners $(\mathrm{n}=10,1 \%)$, time constraints $(\mathrm{n}=18,3 \%)$, and non-resident cases $(n=6,1 \%)$. Of the remaining 532 deaths, 293 (55\%) died in the community. ${ }^{16}$

The median age was 53 years (interquartile range (IQR) 40-59) for cases and 53 years (IQR 40-58.5) for controls; $60 \%$ of cases and $64 \%$ of controls were female. Cases and controls were similar in terms of family history of asthma $(25 \% \mathrm{v}$ $24 \%$ ), evidence of atopy (39\% $v 41 \%)$, history of smoking (58\% v 59\%), and major non-respiratory illness (44\% v 43\%). Cases were more likely to have had an earlier age of asthma onset (median age 30 years for cases $v 33$ years for controls, $\mathrm{p}=0.02)$, to have had mention of COPD $(42 \% \vee 35 \%$, $\mathrm{p}=0.005)$, and to be recorded by their general practitioner as obese $(31 \% \vee 25 \%, \mathrm{p}=0.02)$. Occupation was mentioned for 91 cases and 120 controls and, of these, similar proportions were in manual occupations (cases $46 \%$, controls $48 \%) .{ }^{16}$ 
Table 1 Use of general and asthma services in primary care by cases $(n=532)$ and control subjects $(n=532)$

\begin{tabular}{|c|c|c|c|c|c|c|c|c|}
\hline & \multicolumn{4}{|c|}{1 year before index date } & \multicolumn{4}{|c|}{$1+$ to 5 years before index date } \\
\hline & Cases & Controls & Odds ratio & $95 \% \mathrm{Cl}$ & Cases & Controls & Odds ratio & $95 \% \mathrm{Cl}$ \\
\hline \multicolumn{9}{|l|}{ Use of general services } \\
\hline $\begin{array}{l}\text { Mean (SD) no of days since last } \\
\text { practice contact }\end{array}$ & $\begin{array}{l}86.5(156.5) \\
n=528\end{array}$ & $\begin{array}{l}48.3(82.5) \\
n=526\end{array}$ & $\begin{array}{l}1.09^{* * *} \text { per } \\
\text { month ( } 30 \text { days) }\end{array}$ & 1.05 to 1.13 & NA & NA & NA & NA \\
\hline $\begin{array}{l}\text { Mean (SD) no of general practice } \\
\text { contacts }\end{array}$ & $\begin{array}{l}9.8(8.8) \\
\mathrm{n}=529\end{array}$ & $\begin{array}{l}11.1(8.6) \\
n=529\end{array}$ & $\begin{array}{l}0.90^{* *} \text { per } \\
5 \mathrm{GP} \text { contacts }\end{array}$ & 0.84 to 0.98 & $\begin{array}{l}30.6(24.5) \\
n=528\end{array}$ & $\begin{array}{l}34.0(25.9) \\
n=530\end{array}$ & $\begin{array}{l}0.97^{*} \text { per } \\
5 \text { GP contacts }\end{array}$ & 0.95 to 1.00 \\
\hline $\begin{array}{l}\text { Mean (SD) no of respiratory } \\
\text { consultations }\end{array}$ & $\begin{array}{l}4.9(5.1) \\
n=528\end{array}$ & $\begin{array}{l}5.8(5.6) \\
n=529\end{array}$ & $\begin{array}{l}0.85^{* *} \text { per } \\
5 \mathrm{GP} \text { contacts }\end{array}$ & 0.75 to 0.96 & $\begin{array}{l}14.3(14.3) \\
n=527\end{array}$ & $\begin{array}{l}14.2(14.7) \\
n=530\end{array}$ & $\begin{array}{l}1.00 \text { per } \\
5 \mathrm{GP} \text { contacts }\end{array}$ & 0.96 to 1.05 \\
\hline $\begin{array}{l}\text { No of home visits for respiratory } \\
\text { illness (\%) }\end{array}$ & & & & $* \star *$ & & & & $* * *$ \\
\hline 0 & 60.7 & 63.2 & 1.00 & - & 54.3 & 60.2 & 1.00 & - \\
\hline $1-2$ & 25.0 & 27.4 & 0.95 & 0.72 to 1.26 & 22.2 & 23.1 & 1.08 & 0.79 to 1.48 \\
\hline $3+$ & 13.7 & 8.8 & 1.72 & 1.13 to 2.62 & 22.7 & 16.4 & 1.61 & 1.15 to 2.26 \\
\hline Missing & 0.6 & 0.6 & & & 0.8 & 0.4 & & \\
\hline $\begin{array}{l}\text { No of home visits for non-respiratory } \\
\text { illness (\%) }\end{array}$ & & & & $* * *$ & & & & \\
\hline 0 & 76.7 & 83.8 & 1.00 & - & 64.3 & 64.8 & 1.00 & - \\
\hline $1-2$ & 14.7 & 10.7 & 1.56 & 1.06 to 2.29 & 20.9 & 23.7 & 0.93 & 0.69 to 1.25 \\
\hline $3+$ & 8.1 & 4.9 & 1.85 & 1.10 to 3.11 & 14.1 & 11.1 & 1.30 & 0.89 to 1.89 \\
\hline Missing & 0.6 & 0.6 & & & 0.8 & 0.4 & & \\
\hline \multicolumn{9}{|l|}{ Use of asthma services } \\
\hline Asthma clinic attended (\%) & 12.6 & 13.3 & 0.94 & 0.65 to 1.36 & 25.0 & 28.2 & 0.84 & 0.64 to 1.11 \\
\hline Prescription of home nebuliser (\%) & 36.5 & 32.3 & 1.22 & 0.94 to 1.58 & 35.2 & 29.1 & $1.34^{*}$ & 1.03 to 1.76 \\
\hline Prescription of home oxygen (\%) & 12.0 & 5.1 & $2.73^{* * *}$ & 1.67 to 4.46 & 10.0 & 4.5 & $2.64^{* * *}$ & 1.53 to 4.56 \\
\hline Mention of wheelchair (\%) & 3.6 & 1.5 & $2.38^{*}$ & 1.04 to 5.44 & 3.9 & 1.1 & $3.58^{* *}$ & 1.44 to 8.88 \\
\hline Disability allowance application (\%) & 7.3 & 9.8 & 0.72 & 0.46 to 1.14 & 13.7 & 13.2 & 1.06 & 0.74 to 1.51 \\
\hline Asthma drug non-compliance (\%) & 6.4 & 6.4 & 1.00 & 0.61 to 1.65 & 13.5 & 12.0 & 1.14 & 0.79 to 1.65 \\
\hline Poor inhaler technique (\%) & 6.2 & 5.5 & 1.16 & 0.67 to 2.00 & 11.1 & 9.8 & 1.17 & 0.79 to 1.73 \\
\hline Asthma repeated non-attendance (\%) & 4.5 & 3.2 & 1.40 & 0.75 to 2.60 & 9.4 & 5.8 & $1.74^{*}$ & 1.08 to 2.83 \\
\hline
\end{tabular}

\section{Use of primary care services}

The mean (SD) length of time between the last general practice contact and the index date was 86.5 (156.5) days for cases and 48.3 (82.5) days for controls ( $\mathrm{p}<0.001$, table 1$)$. Subtracting length of stay prior to death for cases dying in hospital had little effect (84.4 (156.7) days $v 48.3$ (82.5) days, $\mathrm{p}<0.001)$. Cases had significantly fewer general practice contacts (odds ratio $0.90,95 \%$ confidence interval (CI) 0.84 to $0.98, \mathrm{p}=0.009$, per five contacts) and respiratory consultations (0.85 (95\% CI 0.75 to 0.96$) \mathrm{p}=0.006$ per five consultations) in the last year. Conversely, cases had significantly more home visits in the last year for respiratory illness (95\% CI 1.12 ( 1.04 to 1.20$) \mathrm{p}<0.001$ per visit) and for non-respiratory illness ( 1.19 (95\% CI 1.08 to 1.32$) \mathrm{p}<0.001$ per visit).

In the year before the index date, $93 \%$ of patients with a home visit also had two or more recorded surgery visits. The proportion with a prescription of short acting bronhodilators

Table 2 Use of asthma services in secondary care by cases $(n=532)$ and controls $(n=532)$

\begin{tabular}{|c|c|c|c|c|c|c|c|c|}
\hline & \multicolumn{4}{|c|}{1 year before index date } & \multicolumn{4}{|c|}{$1+$ to 5 years before index date } \\
\hline & Cases & Controls & Odds ratio & $95 \% \mathrm{Cl}$ & Cases & Controls & Odds ratio & $95 \% \mathrm{Cl}$ \\
\hline \multicolumn{9}{|c|}{$\begin{array}{l}\text { No of outpatient appointments for } \\
\text { asthma (respiratory or general) }\end{array}$} \\
\hline 0 & 64.7 & 62.0 & 1.00 & - & 52.4 & 53.2 & 1.00 & - \\
\hline $1-2$ & 16.2 & 19.0 & 0.83 & 0.60 to 1.14 & 13.2 & 14.3 & 0.93 & 0.64 to 1.34 \\
\hline $3+$ & 19.2 & 19.0 & 0.98 & 0.71 to 1.35 & 34.4 & 32.5 & 1.07 & 0.82 to 1.40 \\
\hline \multicolumn{9}{|c|}{ No of acute asthma admissions } \\
\hline 0 & 64.8 & 65.0 & 1.00 & - & 58.8 & 57.0 & 1.00 & - \\
\hline $1-2$ & 22.6 & 24.4 & 0.92 & 0.68 to 1.25 & 22.2 & 22.9 & 0.93 & 0.69 to 1.27 \\
\hline $3-4$ & 7.3 & 7.7 & 0.93 & 0.58 to 1.49 & 6.6 & 9.6 & 0.67 & 0.43 to 1.07 \\
\hline $5+$ & 5.3 & 2.8 & 1.83 & 0.97 to 3.46 & 12.4 & 10.5 & 1.16 & 0.77 to 1.74 \\
\hline \multicolumn{9}{|c|}{ No of days admitted for asthma } \\
\hline 0 & 64.8 & 65.0 & 1.00 & - & 58.8 & 57.0 & 1.00 & - \\
\hline $1-7$ & 13.0 & 14.7 & 0.88 & 0.61 to 1.28 & 11.8 & 12.8 & 0.90 & 0.62 to 1.33 \\
\hline $8-14$ & 7.0 & 8.8 & 0.77 & 0.48 to 1.22 & 8.1 & 10.3 & 0.76 & 0.49 to 1.17 \\
\hline $15+$ & 15.2 & 11.5 & 1.36 & 0.93 to 1.98 & 21.1 & 19.7 & 1.05 & 0.77 to 1.44 \\
\hline \multirow{2}{*}{\multicolumn{9}{|c|}{ No of A\&E attendances for asthma }} \\
\hline & & & & & & & & \\
\hline 0 & 93.4 & 94.5 & 1.00 & - & 92.3 & 95.1 & 1.00 & - \\
\hline $1-2$ & 5.5 & 5.1 & 1.10 & 0.64 to 1.88 & 7.0 & 4.3 & 1.61 & 0.94 to 2.74 \\
\hline $3+$ & 1.1 & 0.4 & 2.94 & 0.59 to 14.6 & 0.8 & 0.6 & 1.34 & 0.29 to 6.08 \\
\hline
\end{tabular}

Data presented as percentages.

Odds ratios and $p$ values for trend calculated using conditional logistic regression, ignoring the missing and unknown categories.

Odds ratios are adjusted for sex.

${ }^{*} p<0.05,{ }^{* *} p<0.01,{ }^{* * *} p<0.001$ (trend) 
in the $1-5$ years before index date was only slightly higher among those with one or more home visits in the last year $(91 \%(420 / 461) \vee 86 \%(511 / 597))$. However, this difference was more pronounced among cases (95\% (226/239) v 87\% $(251 / 290))$ than controls $(87 \%(194 / 222) v 85 \%(260 / 307))$.

\section{Use of asthma services in primary care}

In the year before the index date only $13 \%$ of cases and 13\% of controls had evidence of attending a formal primary care based asthma clinic (table 1). In the 4 years before that, repeated non-attendance for asthma care was more commonly recorded in the notes of cases than controls (odds ratio $1.74,95 \%$ CI 1.08 to $2.83, \mathrm{p}=0.02$ ) as was possession of a home nebuliser ( 1.34 (95\% CI 1.03 to 1.76$), p=0.03$ ). In the last year these associations were less marked and not statistically significant $(\mathrm{p}>0.05)$. In the last year and in the 4 previous years, more cases than controls had mention of wheelchair $(3.6 \% \vee 1.5 \%$ in the last year) and home oxygen ( $12.0 \% \vee 5.1 \%$ in the last year). Mentions of other relevant aspects of health behaviour including asthma drug noncompliance and poor inhaler technique were similar in cases and controls. The findings on asthma drugs in this casecontrol study are the subject of another paper. ${ }^{17}$

\section{Use of asthma services in secondary care}

Approximately one third of cases (37\%) and controls (33\%) had no history of asthma admission or outpatient consultations for asthma in the previous 5 years (table 2). Only $55 \%$ of both groups attended hospital outpatients in the last five years and attendance was comparable both in the final year and in the four years prior. In the last year 35\% of both groups were admitted to hospital on one or more occasions with asthma; in the four years prior to that, $41 \%$ of cases and $43 \%$ of controls were admitted. Furthermore, in the last five years, cases and controls also had similar patterns of inpatient days for acute asthma (median 20 days for cases and
15 days for controls, excluding those with no admissions). In the same time period only $12 \%$ of cases and $10 \%$ of controls had records of accident and emergency attendance in their primary care notes.

\section{Lung function measurements}

There was no significant difference between cases and controls in the number of occasions when FEV 1 was measured in either primary or secondary care (table 3). In primary care, cases had significantly fewer peak expiratory flow (PEF) recordings than controls in the final 3 months and also in the 9 months before that. In the same periods, mentions of PEF recording in outpatient and discharge letters were also fewer in cases than controls, although not significantly (table 3 ).

\section{The final model}

The final model (table 4) is based on the significant findings of the preliminary analyses (adjusted for sex) of medical service use factors in the year before the index date and PEF recording in the last 3 months. In the first column the odds ratios are presented with adjustment for sex. In the second they are additionally adjusted for each other, with all three factors (number of GP contacts (excluding home visits) and number of home visits, both in the previous year, and the number of PEF measurements taken in the final 3 months) remaining significantly associated with the risk of asthma death. Odds ratios suggest that, in the year before the index date, an additional five general practice contacts (excluding home visits) were associated with an 18\% lower risk of asthma death, an additional home visit with a $14 \%$ higher risk, and an additional PEF taken in the last 3 months was associated with a $17 \%$ lower risk. In the third column, adjustment for markers of asthma severity (COPD, age of asthma onset, prescription of home oxygen and mention of wheelchair in the previous year) and obesity had only a small

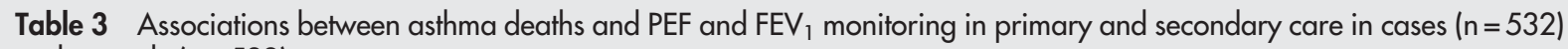
and controls $(n=532)$

\begin{tabular}{|c|c|c|c|c|c|c|c|c|c|c|c|c|}
\hline & \multicolumn{4}{|c|}{3 months before index date } & \multicolumn{4}{|c|}{ 4-12 months before index date } & \multicolumn{4}{|c|}{$1+$ to 5 years before index date } \\
\hline & Cases & Controls & $\begin{array}{l}\text { Odds } \\
\text { ratio }\end{array}$ & $95 \% \mathrm{Cl}$ & Cases & Controls & $\begin{array}{l}\text { Odds } \\
\text { ratio }\end{array}$ & $95 \% \mathrm{Cl}$ & Cases & Controls & $\begin{array}{l}\text { Odds } \\
\text { ratio }\end{array}$ & $95 \% \mathrm{Cl}$ \\
\hline \multicolumn{13}{|l|}{ Primary care } \\
\hline $\begin{array}{l}\text { No of occasions PEF } \\
\text { recorded }\end{array}$ & & & & $* * *$ & & & & * & & & & \\
\hline 0 & 77.8 & 63.2 & 1.00 & - & 60.3 & 54.9 & 1.00 & - & 32.9 & 27.4 & 1.00 & - \\
\hline $1-5$ & 22.0 & 34.8 & 0.50 & 0.38 to 0.67 & 34.4 & 37.4 & 0.83 & 0.64 to 1.07 & 39.1 & 41.2 & 0.78 & 0.58 to 1.06 \\
\hline $6-10$ & 0.2 & 1.9 & 0.09 & 0.01 to 0.70 & 4.1 & 6.4 & 0.59 & 0.34 to 1.02 & 13.9 & 15.2 & 0.75 & 0.51 to 1.11 \\
\hline $10+$ & 0 & 0.2 & & & 1.1 & 1.3 & 0.78 & 0.26 to 2.33 & 14.1 & 16.2 & 0.70 & 0.46 to 1.04 \\
\hline \multicolumn{13}{|l|}{$\begin{array}{l}\text { No of occasions FEV } \\
\text { recorded }\end{array}$} \\
\hline 0 & 99.6 & 99.1 & 1.00 & - & 99.1 & 99.2 & 1.00 & - & 98.5 & 98.3 & 1.00 & - \\
\hline $1-5$ & 0.4 & 0.9 & 0.41 & 0.08 to 2.10 & 0.9 & 0.8 & 1.23 & 0.33 to 4.59 & 1.5 & 1.7 & 0.90 & 0.35 to 2.32 \\
\hline \multicolumn{13}{|c|}{ Secondary care } \\
\hline \multicolumn{13}{|c|}{$\begin{array}{l}\text { No of occasions PEF } \\
\text { recorded in outpatients/ } \\
\text { discharge letters }\end{array}$} \\
\hline 0 & 88.0 & 85.9 & 1.00 & - & 78.9 & 73.5 & 1.00 & - & 58.1 & 58.1 & 1.00 & - \\
\hline $1-5$ & 12.0 & 14.1 & 0.82 & 0.57 to 1.19 & 19.9 & 24.8 & 0.75 & 0.56 to 1.00 & 28.6 & 28.8 & 0.99 & 0.75 to 1.31 \\
\hline $6-10$ & 0 & 0 & & & 1.1 & 1.3 & 0.83 & 0.28 to 2.47 & 7.5 & 7.7 & 0.96 & 0.61 to 1.52 \\
\hline $10+$ & 0 & 0 & & & 0 & 0.4 & & & 5.8 & 5.5 & 1.09 & 0.63 to 1.91 \\
\hline \multicolumn{13}{|l|}{$\begin{array}{l}\text { No of occasions FEV } \\
\text { recorded }\end{array}$} \\
\hline 0 & 95.1 & 94.4 & 1.00 & - & 88.5 & 88.2 & 1.00 & - & 75.8 & 75.2 & 1.00 & - \\
\hline $1-5$ & 4.9 & 5.6 & 0.87 & 0.50 to 1.50 & 11.5 & 11.8 & 0.97 & 0.66 to 1.43 & 19.0 & 21.2 & 0.90 & 0.66 to 1.23 \\
\hline $6+$ & 0 & 0 & & & & & & & 5.3 & 3.6 & 1.46 & 0.80 to 2.65 \\
\hline $\begin{array}{l}\text { Data presented as pe } \\
\text { Odds ratios from con } \\
{ }^{*} p<0.05,{ }^{* *} p<0.01 \text {, }\end{array}$ & ges. & $\begin{array}{l}\text { ression a } \\
\text { d). }\end{array}$ & adjuste & for sex. & & & & & & & & \\
\hline
\end{tabular}


Table 4 Associations between asthma death and use of medical services factors $(n=1052)$

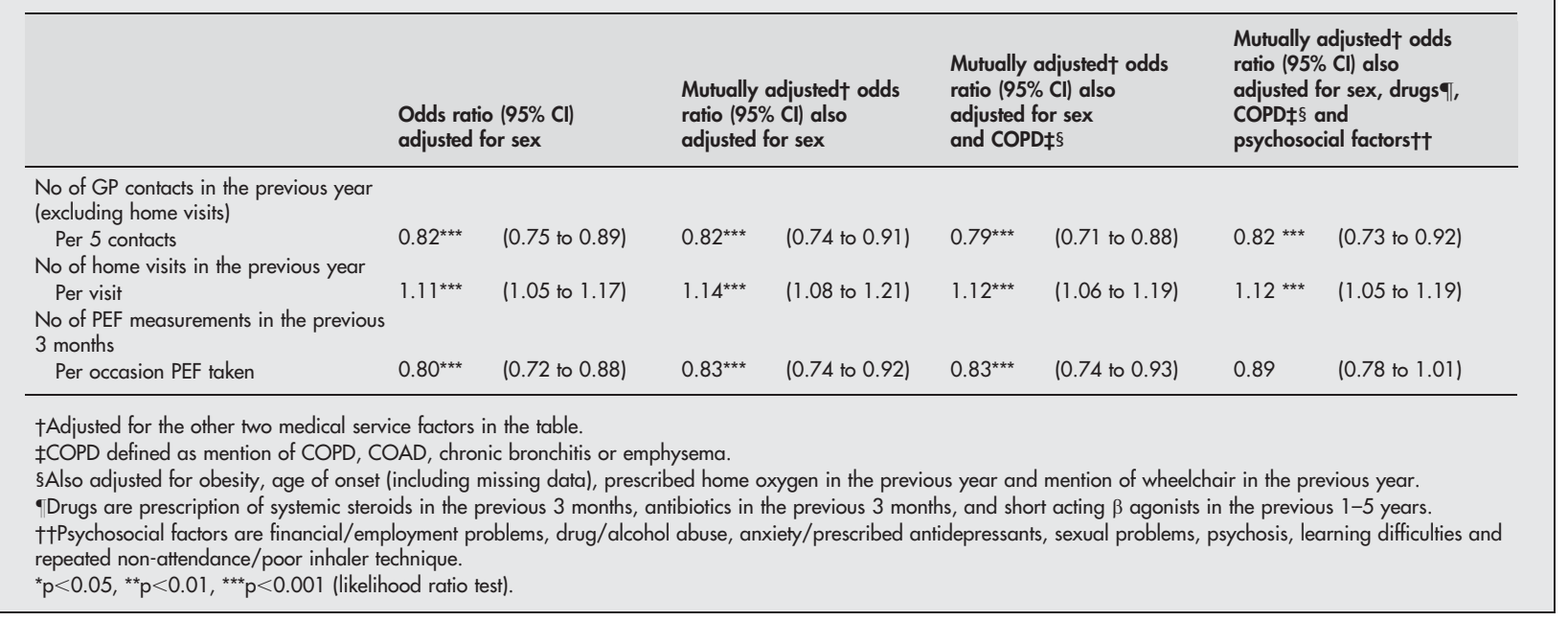

effect on these three apparently independent associations. Further adjustment for prescription of systemic steroids (in the previous 3 months), antibiotics (in the previous 3 months), short acting $\beta$ agonists (in the previous $1-$ 5 years), and the significant psychosocial factors found in a previous analysis of these data ${ }^{16}$ made little difference to associations with GP contact and home visits. However, adjustment for asthma drugs led to an increase in the odds ratio for PEF (0.87 (95\% CI 0.78 to 0.98$)$ ) and, with the addition of psychosocial factors, the association just lost statistical significance ( 0.89 (95\% CI 0.78 to 1.01$) ; \mathrm{p}=0.06)$. For GP contact the association with asthma death differed significantly between age groups $(p=0.015)$. Odds ratios were 0.65 (95\% CI 0.52 to 0.82 ) for those under 45 years of age and 0.88 (95\% CI 0.77 to 1.00 ) for those aged $\geqslant 45$ years. This suggests that, in the year before the index date, an additional five general practice contacts (excluding home visits) were associated with a 35\% lower risk of asthma death in the younger age group and only a $12 \%$ lower risk in the older age group. There was no evidence of any difference in association between age groups for peak flow $(p=0.20)$ or home visits $(p=0.35)$.

\section{Sensitivity analyses}

We considered the possibility of bias stemming from the use of hospital cases that would have been outside the primary care system during their period of stay before death. Of the $236(44 \%)$ cases that died in hospital, 36 had been in hospital for more than seven whole days. Excluding these subjects from the model presented in column 4 of table 4 had little effect on associations with GP contact $(0.80$ (95\% CI 0.71 to $0.90)$ ), home visits (1.11 (95\% CI 1.04 to 1.19$)$ ), or PEF $(0.90$ (95\% CI 0.79 to 1.02$)$ ).

We also investigated the effect of using an alternative adjustment for asthma drug prescription by including age group $(<45,45-64)$ specific terms for oral steroids in the previous 4-12 months, antibiotics in the previous 412 months, and short acting bronchodilators in the previous $1-5$ years. This had little effect on associations with GP contact ( 0.81 ( $95 \%$ CI 0.72 to 0.92 ) per five contacts), home visits (1.10 (95\% CI 1.03 to 1.18 ) per visit), and PEF (0.85 ( $95 \%$ CI 0.75 to 0.96 ) per occasion). The return to significance of the association with PEF may simply reflect the lack of asthma drug data in the new model for the period of observation (0-3 months). However, the association with GP contact no longer differed significantly between age groups ( 0.70 (95\% CI 0.55 to 0.89 ) for subjects aged under 45 years and 0.85 (95\% CI 0.74 to 0.99 ) for those aged 45 and over $(p=0.16)$. These results were virtually unchanged when we added age group $(<45,45+)$ specific terms for the prescription of inhaled steroids in the $1-5$ years before the index date.

When we investigated the effect of adding prescription of inhaled steroids in the 3 months before the index date to the model presented in column 4 of table 4 , the results were little changed although the association with PEF recordings just returned to statistical significance (OR 0.88 (95\% CI 0.78 tol.00); $\mathrm{p}=0.04)$.

\section{DISCUSSION}

This case-control study is by far the largest yet reported, was population based, and included older subjects up to 65 years of age, making it the most representative of severe asthma and asthma deaths. It included asthma deaths with important co-morbidities such as COPD, ${ }^{15}$ since these are likely to increase the risk of death. The data were largely extracted by an unbiased method blind to case-control status.

Shortcomings of primary care records such as lack of standardisation in diagnoses and in the recording of patient reported symptoms should have equally affected cases and controls. The low level of accident and emergency attendance in both cases and controls may be due to under-reporting in general practice records. It was difficult to assess whether patients possessed self-management plans (symptom or PEF based) as these are not generally recorded in primary care records. Controls were only drawn from hospitals, but our cases and controls were well balanced in terms of age, sex and recent asthma admission, a possible marker of asthma severity. ${ }^{12}{ }^{18}$ Furthermore, possible bias due to length of stay before death for cases dying in hospital appeared to have little impact on the results.

Other investigators have used asthma admission in the year before death, treatment with three or more classes of drugs, and recent courses of oral steroids as markers of asthma severity. ${ }^{18-20}$ We found little difference in recent asthma admissions whereas systemic steroids were prescribed less frequently for cases. ${ }^{17}$ Lung function was not measured consistently and could not be used as a marker of severity; $41 \%$ of cases and $30 \%$ of controls had no mention of $\mathrm{PEF}$ or $\mathrm{FEV}_{1}$ recordings in the last year. More mentions of COPD and earlier age of asthma onset suggested that cases had more severe disease than controls. These markers of severity along with obesity, wheelchair use, home oxygen 
prescription, systemic steroid, short acting bronchodilator and antibiotic use were adjusted for in the analyses.

The main finding of this study was the lower rate of consultations in primary care by cases compared with controls, even after controlling for severity and psychosocial factors and irrespective of the greater number of home visits. This association appeared to be slightly stronger in those aged under 45 years, a group that comprised few cases (7\%) with co-existing COPD, although any difference in the association by age group may be explained, at least in part, by age related differences in the associations between asthma death and prescribed drugs, in particular antibiotics (data not shown).

The greater use of home visits among cases suggests that their disease could have been more severe (acutely, chronically, or both). Alternatively, it could mean that these patients were not using preventive therapy as effectively. This is supported by the slightly higher proportion of cases with a prescription for short acting bronchodilators in the previous $1-5$ years. ${ }^{17}$ However, their significantly greater use of home visits for non-respiratory illness in the last year might indicate that these cases were unable to use services "appropriately" due to other factors. While cases were more likely to have co-existent COPD, the associations with asthma death persisted after adjustment for this.

The negative association with PEF recordings dropped just below the $5 \%$ significance level when we additionally adjusted for psychosocial factors in the final model (table 4). Nevertheless, fewer PEF recordings in cases suggests that lack of monitoring may be associated with inadequate asthma management, in line with the findings from confidential enquiries into asthma deaths. ${ }^{2468}$ Prescription of systemic steroids in the last 3 months was also positively associated with PEF recording in both cases and controls over the same time period (data not shown). However, this did not appear to explain fully the association between lack of PEF recording and asthma death (table 4). Moreover, our information on drugs is not without bias due to problems in coding around the index date, ${ }^{17}$ and tells us nothing about dosage or whether prescription represented long term treatment or a change in treatment in the short term. The possibility that PEF recording is associated with a lower risk of asthma death because it leads to more appropriate immediate treatment cannot be discounted.

When psychosocial factors were included in our analysis, they did not explain the association between practice contacts and asthma death. Although a higher proportion of controls had mention of anxiety, ${ }^{16}$ this did not appear to explain differences in service use. However, there are some patient factors that we were unable to elicit because they are not generally recorded in primary care records. It may be that some vulnerable patients have a poor perception of the severity of their acutely worsening airflow obstruction and/or their level of self-monitoring may be low or non-existent. Some patients may panic and seek treatment more readily, while others may be in a state of denial and delay treatment. All these factors could have an impact on the use of medical services, particularly in the short term.

This study has found a number of associations between medical service use and mortality but, because it is observational in nature, it cannot in itself satisfactorily resolve questions of cause and effect or underlying mechanisms. The resolution of such questions will require more detailed studies using purpose built methods-including clinical trials where appropriate-rather than relying, as we have done, on routine records. Nevertheless, we conclude that asthma death is associated with lesser use of primary care services and that a better understanding of both the practice and patient factors involved may offer possibilities for reducing asthma death.

\section{ACKNOWLEDGEMENTS}

The authors are grateful for the advice and support of the steering committee, the Severe Morbidity and Mortality Group of the National Asthma Campaign, which included: J Ayres (Chairman), B Harrison (past Chairman), D Stableforth, M Burr, W Berrill, V Fox, T Williams, S Wright, C Bucknall, F Chung, C Godley, G Houghton, T MacKay, S McKenzie, G Mohan, J Poundsford and A Ross. The authors acknowledge the advice of R Beasley, J Crane and N Pearce of the Wellington Asthma Research Group who are involved with another part of this study; Jennifer Taylor and research assistants B Khoshaba, B Davies, B Eldridge, S MacArthur and M Wardroper for carrying out field work; the medical students who undertook data extraction; and the large number of general practitioners, health authority, and hospital personnel who assisted the study. The Office for National Statistics and the General Register Office supplied copies of death certificates

\section{Authors' affiliations}

B K Butland, H R Anderson, Division of Public Health Sciences, St George's, London SW17 ORE, UK

P M Sturdy, Institute of Community Health Sciences, Barts and the London, Queen Mary's School of Medicine and Dentistry, London, UK J G Ayres, Department of Environmental and Occupational Medicine, Liberty Safe Work Research Centre, University of Aberdeen, UK J M Bland, Department of Health Sciences, University of York, York, UK B D W Harrison, Department of Respiratory Medicine, Norfolk and Norwich University Hospital NHS Trust, Norfolk, UK

C Peckitt, Institute of Cancer, University of London, UK

C R Victor, Professor of Gerontology and Health Services Research, Head of School of Health and Social Care, University of Reading, UK

This study was funded jointly between the National Research and Development Asthma Management Programme (contract number AM1 / 05/002) and the National Asthma Campaign through a grant from Glaxo Wellcome (now GlaxoSmithKline).

Competing interests: none declared

Patricia Sturdy was responsible for coordinating the study, undertaking field work, data extraction and drafting the paper. Barbara Butland supervised and contributed to the statistical analyses, advised on interpretation and undertook drafting. Ross Anderson, as the principal investigator, designed and supervised the whole project and contributed to the drafting. Jon Ayres and Brian Harrison helped design the study, undertook validation, and contributed to drafting. Martin Bland was partly responsible for the design of the study and for the statistical analysis and interpretation. Clare Peckitt carried out the statistical analysis. Christina Victor advised on study design.

\section{REFERENCES}

1 Anon. Lung and Asthma Information Agency, 2000.

2 Harrison BD, Slack R, Berril WT, et al. Results of a national confidential enquiry into asthma deaths. Asthma J 2000;5:180-6.

3 Bucknall CE, Slack R, Godley CC, et al. Scottish Confidential Inquiry into Asthma Deaths (SCIAD), 1994-6. Thorax 1999;54:978-84.

4 Burr ML, Davies BH, Hoare A, et al. A confidential inquiry into asthma deaths in Wales. Thorax 1999:54:985-9.

5 Jones K, Berrill WT, Bromly CL, et al. A confidential enquiry into certified asthma deaths in the North of England, 1994-96: influence of co-morbidity and diagnostic inaccuracy. Respir Med 1999;93:923-7.

6 Mohan G, Harrison BD, Badminton RM, et al. A confidential enquiry into deaths caused by asthma in an English health region: implications for general practice. Br J Gen Pract 1996;46:529-32.

7 Innes NJ, Reid A, Halstead J, et al. Psychosocial risk factors in near-fatal asthma and in asthma deaths. J R Coll Physicians Lond 1998:32:430-4.

8 Wareham NJ, Harrison BD, Jenkins PF, et al. A district confidential enquiry into deaths due to asthma. Thorax 1993;48:1117-20.

9 Jalaludin BB, Smith MA, Chey T, et al. Risk factors for asthma deaths: a population-based, case-control study. Aust NZ J Public Health 1999;23:595-600.

10 Campbell DA, McLennan G, Coates JR, et al. A comparison of asthma deaths and near-fatal asthma attacks in South Australia. Eur Respir J 1994;7:490-7.

11 Kolbe J, Fergusson W, Vamos M, et al. Case-control study of severe life threatening asthma (SLTA) in adults: demographics, health care, and management of the acute attack. Thorax 2000;55:1007-15.

12 Rea HH, Scragg R, Jackson R, et al. A case-control study of deaths from asthma. Thorax 1986;41:833-9.

13 Sudo M, Kobayashi $H$, Nakagawa T, et al. A comparison of asthma deaths and near-fatal asthma attacks (in Japanese). Arerugi - Jpn J Allergol 1996;45: 1262-9 
14 Kesten S, Chew R, Hanania NA. Health-care utilization after near-fatal asthma. Chest 1995;107:1564-9.

15 Silva GE, Sherrill DL, Guerra S, et al. Asthma as a risk factor for COPD in a longitudinal study. Chest 2004;126:59-65.

16 Sturdy PM, Victor CR, Anderson HR, et al. Psychological, social and health behaviour risk factors for deaths certified as asthma: a national case-control study. Thorax 2002;57:1034-9.

17 Anderson HR, Ayres JG, Sturdy PM, et al. Bronchodilator treatment and asthma deaths: a case control study. BMJ 2005;330:117.
18 Crane J, Pearce N, Flatt A, et al. Prescribed fenoterol and death from asthma in New Zealand, 1981-83: case-control study. Lancet 1989; 1:917-22.

19 Grainger J, Woodman K, Pearce N, et al. Prescribed fenoterol and death from asthma in New Zealand, 1981-7: a further case-control study. Thorax 1991;46:105-11.

20 Pearce N, Grainger J, Atkinson M, et al. Case-control study of prescribed fenoterol and death from asthma in New Zealand, 1977-81. Thorax 1990;45:170-5.

\section{LUNG ALERT}

Combination antibiotic susceptibility testing in CF: disappointing clinical results

A Aaron SD, Vandemheen KL, Ferris W, et al. Combination antibiotic susceptibility testing to treat exacerbations of cystic fibrosis associated with multiresistant bacteria: a randomised, double-blind, controlled clinical trial. Lancet 2005;366:46371

$\mathrm{P}$ atients with cystic fibrosis (CF) are often colonised with multiresistant organisms. In vitro data suggest that bactericidal activity may result from antibiotic synergy even if species are resistant to individual agents on routine resistance testing. Simultaneously testing the bactericidal activity of two or more antibiotics (multiple combination bactericidal antibiotic testing, MCBT) is one approach that has been suggested to combat this problem.

This multicentre, prospective, double blind, randomised controlled trial investigated the in vivo effects of selecting antibiotics for exacerbations of CF, based on MCBT versus conventional sensitivity testing. Sputum was tested every 3 months for up to 4 years from 251 patients with CF over 12 years of age who were chronically infected with multiresistant organisms. Both testing methods were used for each sample. Using the results, combinations of two antibiotics with or without nebulised tobramycin were recommended by two separate investigators-one using the MCBT results and the other the conventional sensitivity results.

One hundred and thirty two patients developed exacerbations and were randomised; 64 received MCBT directed therapy and 68 conventionally guided therapy. The primary end point was time to the next exacerbation and secondary end points were changes in sputum bacteria density, $\mathrm{FEV}_{1}, \mathrm{FVC}$, dyspnoea, white cell count, C reactive protein and erythrocyte sedimentation rate, and length of hospital stay. There was no difference in the primary end point between the two groups ( 85 days in the MCBT group $v 79$ days in the conventional group). The reduction in white cell count was greater in the MCBT group $(\mathrm{p}=0.02)$ but hospital stay was 3 days longer $(p=0.03)$. Otherwise, no significant differences were observed.

Caution must be taken when judging the value of tests which appear useful in vitro: this may not necessarily translate to clinical benefit.

J Holme

Specialist Registrar, University Hospital of North Staffordshire, Stoke-on-Trent, UK; jayne.holme1@btinternet.com 